\title{
Changes Regarding Attitudes Towards Ethnic and Cultural Diversity in Sweden: The Diversity Barometer (2005-2018)
}

\author{
Fereshteh Ahmadi ${ }^{1}$, Mehrdad Darvishpour ${ }^{2}, \&$ Irving Palm $^{3}$ \\ ${ }^{1}$ Full Professor in Sociology, Department of Social Work and Psychology, University of Gävle, Gävle, Sweden \\ ${ }^{2}$ Associate Professor, Department of Social Work, Academy of Health and Welfare, Mälardalen University, Mälardalen, \\ Sweden \\ ${ }^{3}$ Associate Professor, Department of Sociology, Uppsala University, Uppsala, Sweden \\ Correspondence: Fereshteh Ahmadi, Full professor in Sociology, Department of Social Work and Psychology, University \\ of Gävle, Gävle, Sweden.
}

Received: June 5, 2020

Accepted: July 13, 2020

Available online: July 22, 2020

doi:10.11114/ijsss.v8i5.4937

URL: https://doi.org/10.11114/ijsss.v8i5.4937

\begin{abstract}
This article aims to discuss changes in attitudes towards immigrants in Sweden from 2015 onwards, based on the results of the longitudinal Diversity Barometer studies from 2005-2014, 2016 and 2018. The Diversity Barometer studies are based on a national, representative, and randomly selected sample from the Swedish population, with a new sample selected each time. We have analyzed the changes from a sociological perspective, using theories such as contact theory and group conflict theory. The results show an increase in negative attitudes towards ethic and cultural diversity generally, and towards immigrants specifically. Diversity in culture and religion - especially towards Islam - is more negatively perceived as compared to diversity in the work domain. Societal groups with extensive experience from contact with foreigners, those who identify themselves as women, those who are more educated, younger people and city dwellers, have all a more positive attitude towards diversity than others.
\end{abstract}

Keywords: Swedish population, migration, ethnic and cultural diversity, diversity barometer

\section{Introduction}

Swedes' attitudes towards immigration and ethnic diversity have been studied and presented in The Diversity Barometer studies for the period 2004-2014 (Ahmadi, Mella, Palm \& Darvishpour, 2015), 2016 (F. Ahmadi, Darvishpour, N. Ahmadi \& Palm, 2018) and 2018 (Ahmadi \& Palm, 2018) ${ }^{\mathrm{i}}$. The results from 2016 and 2018 are important since these studies were conducted after the 2015 refugee influx, which increased the population of foreign-born Swedes by 163.000 (Migrationsverket [Swedish Migration Board], 2018). Additionally, after 2015, the Swedish refugee and immigration policy became more restrictive regarding newly arrived refugees. The studies show a slight increase of positive attitudes towards ethnic diversity and immigrants. The increased number of people applying for refugee status in Sweden in 2015 may have had an impact on these attitudes. The earlier central idea of solidarity has been replaced by a focus on national security.

The increased number of asylum seekers in Sweden and elsewhere in Europe has actualized political and social aspects such as human rights, citizenship, power, democracy and integration. The states' national security has been emphasized instead of the universal rights; here we address to what is usually called "securitization" (Siegel \& Nagy, 2018). A dislocation of approach can be perceived, which means that immigration and especially refugees are considered to undermine the national culture, social welfare and unity (Ahmadi et al., 2018; Asztalos Morell \& Darvishpour, 2018). This in turn leads to the idea that refugees pose a threat towards the national collective identity. The research from 2016 and 2018 testifies to the fact that these changes in attitudes have actually occurred in the Swedish population.

Contact between ethnic and non-ethnic Swedes, especially Muslims, and the attitudes towards them, is a question that that may have significance to understanding the problem of social inclusion and exclusion. When cultural and ethnic diversity are perceived negatively, stigmatization, discrimination, exclusion, and normalization of prejudices against some groups may occur, creating tensions that may escalate into violence in different parts of society.

A quantitative study by Waisman and Larsen (2016) shows that negative attitudes towards immigrants in Sweden, 
especially those from Africa and Asia, has negative consequences on the immigrants' income, wellbeing, and overall quality of life. Negativity towards refugees is also associated with increased vulnerability and a negative effect on health, wellbeing and integration of unaccompanied refugee children (Waisman \& Larsen, 2016; Darvishpour \& Månsson, 2019; Asztalos Morell \& Darvishpour, 2018).

Negative attitudes towards immigrants, cultural and ethnic diversity can make it difficult for immigrants and refugees to join and/or stay on the labor market, causing more segregation and marginalization of populations with foreign background (Bursell, 2015). Previous research shows that the risks for increased marginalization among already marginalized groups is higher with increased negative attitudes towards immigrants and refugees. The negative attitudes have also been associated with increased hate crimes towards migrant and refugee populations (Wigerfelt \& Wigerfelt, 2017).

In this article, we examine changes in attitudes towards immigrants in Sweden since 2015. The article is limited to general positive and negative attitudes towards ethnic diversity, and experiences of contact with people with foreign background.

\section{Method}

Target group in this study is adults between 18 and 75 years-old living in Sweden. A random sample based on SPAR's ${ }^{\text {ii }}$ register has been selected in order to secure a representative sample. The data has been collected using a postal questionnaire.

The sample size is 613 respondents. Regarding the age distribution, the sample contains more older people than younger people which is representative of the Swedish population, even though the sample is slightly more skewed towards the older generations. The age group 18-30 years is only $9 \%$ of the sample ( $<100$ respondents), thus, the results from this age group should be interpreted cautiously. The age group 31-50 years is also slightly underrepresented in relation to the actual Swedish population, whereas the older age groups are to some extent overrepresented (see Diagram 1). The results obtained from previous Diversity Barometer studies of 2005-2014 and 2016 show that the higher the age of respondents, the higher the probability of having negative attitudes towards ethnic diversity and immigration (Ahmadi et al., 2015).

The distribution between men and women is relatively balanced with slightly more women than men, when compared to the actual Swedish population. Considering education, we see a slight underrepresentation of respondents with high school education, and an overrepresentation of those with university education ${ }^{\text {iii }}$.

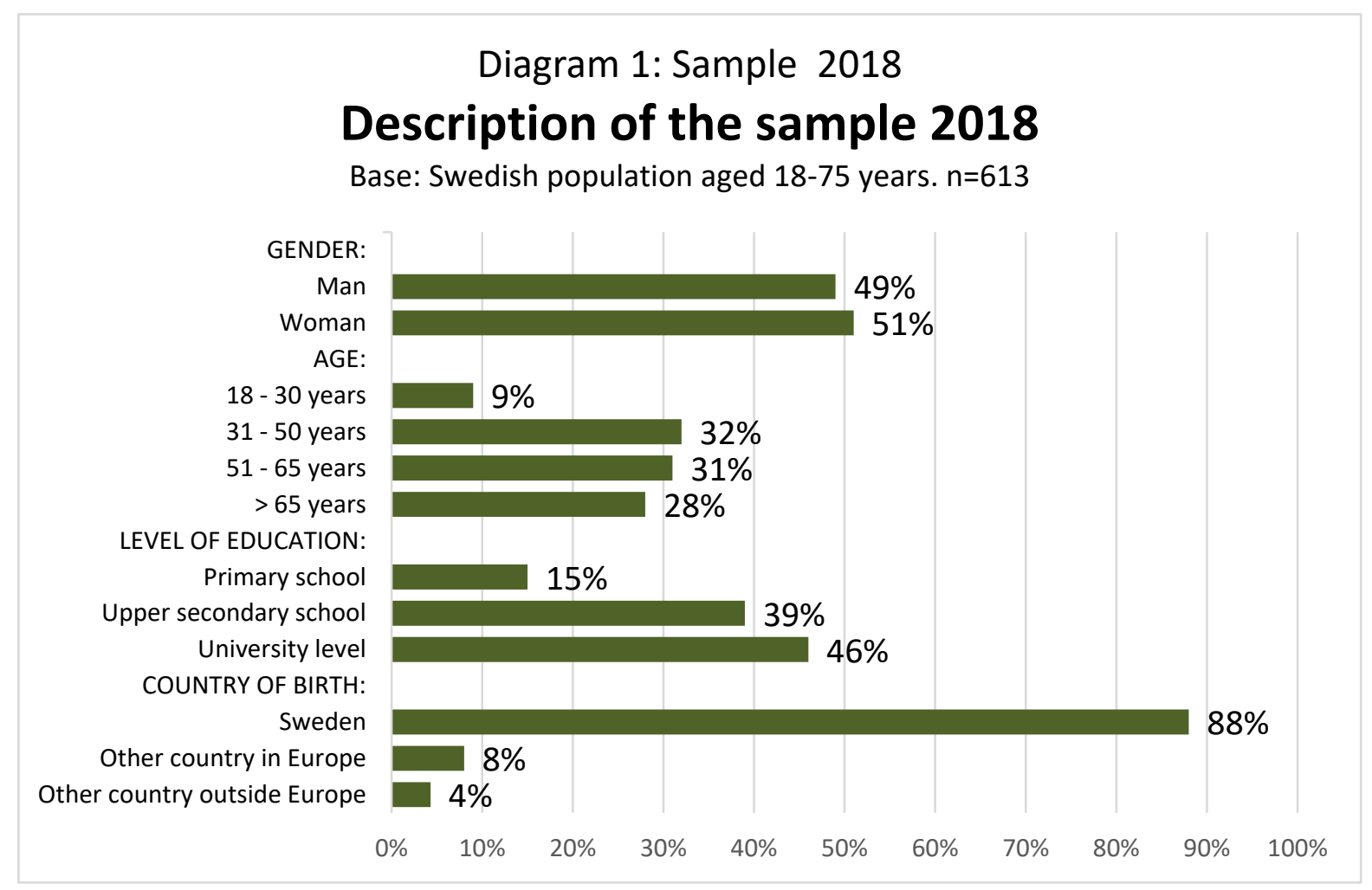

Diagram 1. Description of the sample 
About the ethnic background in this sample, it is worth noting that as many as $88 \%$ are born in Sweden, which is a higher representation of Swedish-born respondents in relation to the actual Swedish population. According to Statistics Sweden, $19.1 \%$ of the Swedish population in December 2018 were born in another country.

The study results, analysis and discussion are presented in the next sections.

\section{Results}

The results are presented under three subsections: (1) experiences of contact with people with a foreign background, (2) general positive attitudes towards diversity, and (3) general negative attitudes towards diversity. In addition, the results are presented for each variable in relation to gender, age and education level. The results are presented in comparison with the previous Diversity Barometer studies from 2016 (F. Ahmadi, Palm \& N. Ahmadi, 2016) and 2018 (Ahmadi \& Palm, 2018).

\subsection{Experiences of Contact with People with Foreign Background}

As the study shows, $38 \%$ of the respondents have at least monthly contact with people from other Nordic countries. $22 \%$ have daily contact with people from countries neighboring Sweden, which is almost similar to contact with people from European countries outside the Nordic region.

It should be noted that contact with people from European countries outside the Nordic region is higher as compared to contact with people from non-European counties. Only $10 \%$ have contacts with people from Middle East at least once a month. The percentage is almost the same (9\%) for respondents that have contact with this group on daily basis.

Swedes have most contact with people from Asia, Latin America, Africa (listed in descending order) and least contact with people from North America and Australia. This could be explain by the fact that immigrants and refugees in Sweden from North America and Australia are much fewer than those from other parts of the world. It is also noteworthy that approximately $30 \%$ of the respondents mention that they do not have any contact with people from countries outside Europe $^{\text {iv }}$ (Diagram 2).

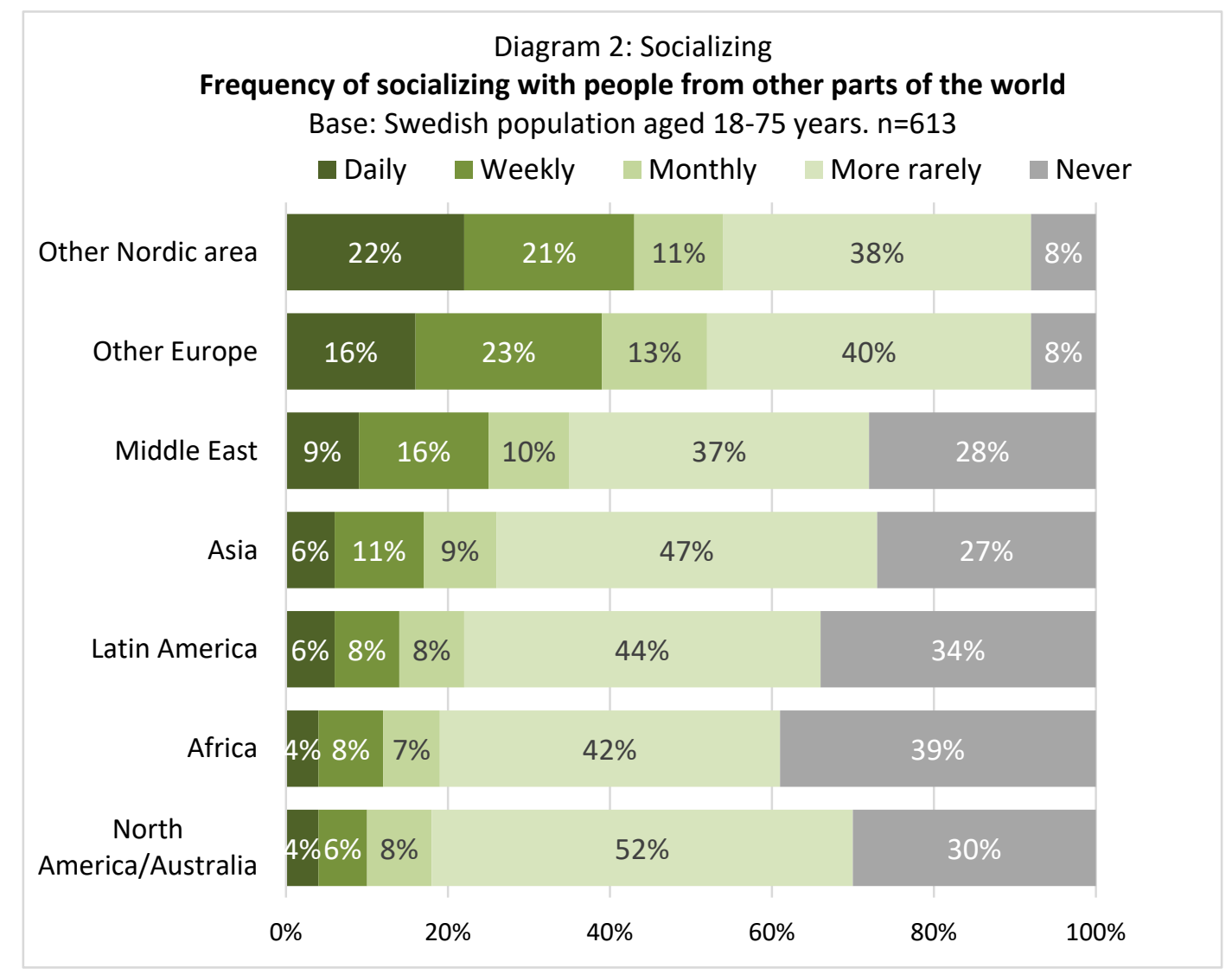

Diagram 2. How often the Swedes interact with people with foreign background 
Diagram 3 indicates that people who have, since a couple of years back, good or very good experiences of colleagues with a foreign background are slightly increasing, currently at $74 \%$ as per the survey from 2018 . This is the highest percentage ever measured, and it shows an increase with 9 percentage units compared to the inaugural measurement. On the other hand, the percentage of people with bad or very bad experiences has been low and stable over the years (9-12\%). The percentage for 2018 is $9 \%$, which is the lowest measured so far. Moreover, comparison of the results from 2005-2014, and those from 2016 shows a slight decrease.

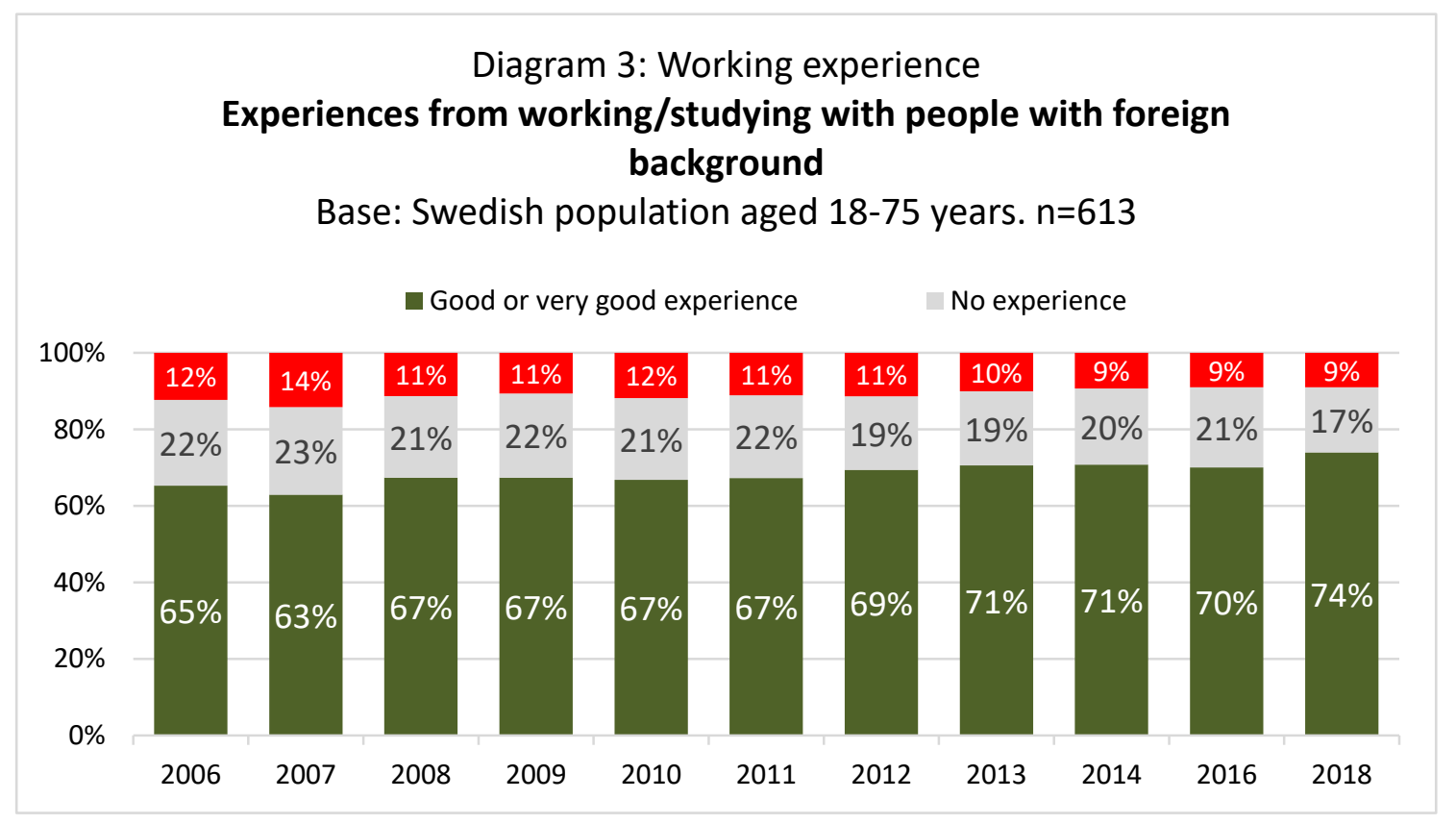

Diagram 3. Good or bad experiences of working/studying with people with foreign background

Gender: A larger percentage of women than men report that they have good or very good experiences of working or studying with people with foreign background. However, the difference is not statistically significant.

This positive trend reported among women in all the measurements since 2005 , reaches its highest at $74 \%$ in 2018 . Less than one in ten women report that they have negative working or studying experiences with people with foreign background, and there has been a marginal reduction by 2 percentage units at the 2018 measurement.

As shown in diagram 4 , about $66 \%$ of the men have positive experiences of working or studying with people with a background from another country. This group with positive experiences has not changed much over the past years. Furthermore, the percentage of men reporting negative experiences in 2018 is 10\%, which is lower than the percentages reported in previous years. 


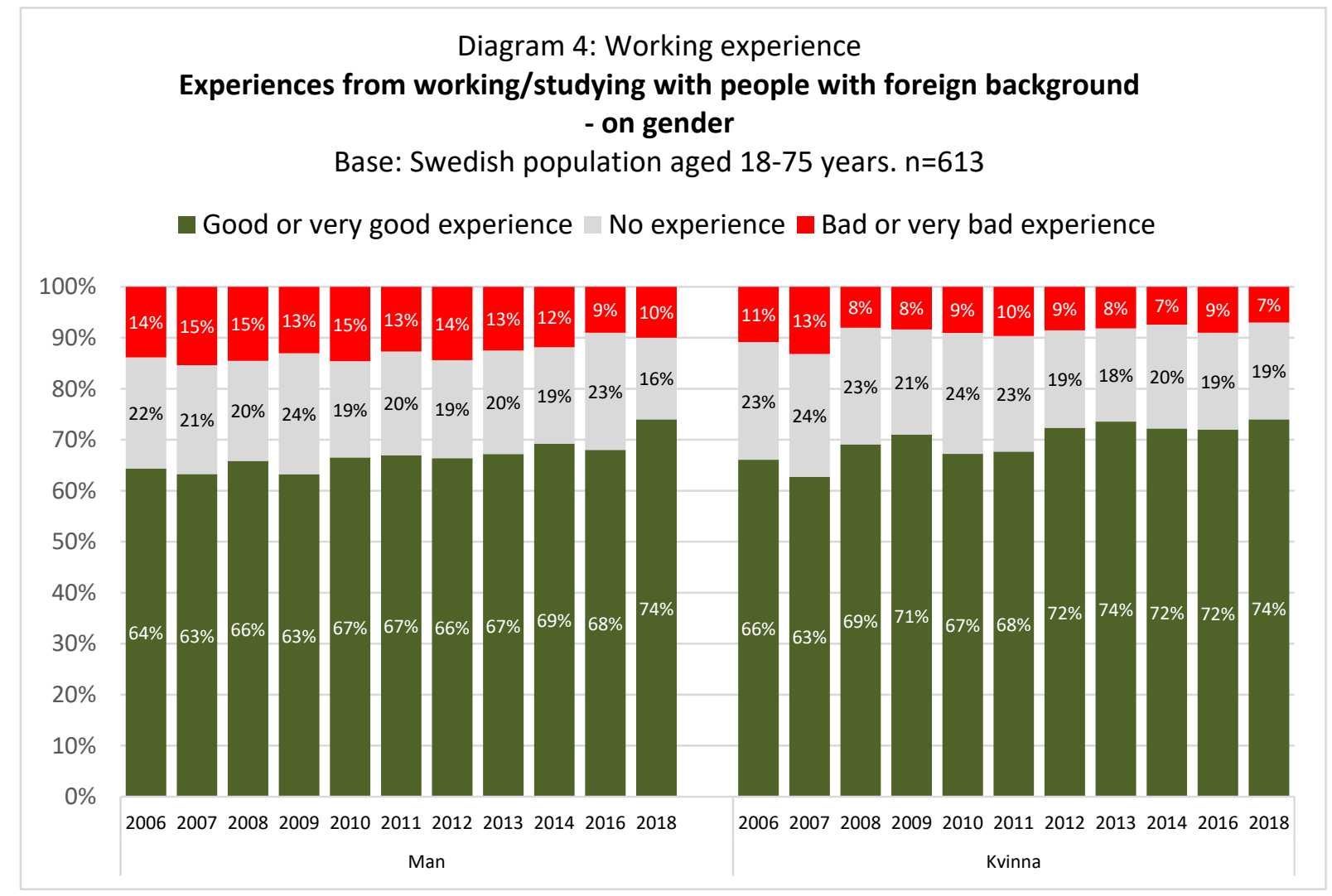

Diagram 4. Good and bad experiences of working or studying with people with foreign background (Gender)

Age: The youngest age group has always had the highest percentage of respondents reporting good experiences of studying or working with people with a foreign background. Since 2013, the percentage had been over $80 \%$, with the current level, and that from 2016 being the highest at $86 \%$.

Age group 31-50 years old now has the same level of good experience from colleagues with foreign background as the youngest age group. This increase is the biggest among all age groups since 2016. Experiences among respondents aged 51-65 years have been stable for the last 5 years. In the oldest age group, respondents reporting good experiences in 2018 are 59\% which is almost the same as in 2016. Many of the respondents in the older age group do not have any experiences with people with foreign background, which could explain the relatively lower level of good experiences. Many of them are retired and rarely meet other people in work-or study-related contexts.

Among the oldest age group the share with good experience is 59 percent, fully comparable with last measurement. The reason that the results for this oldest age group is relatively low is that a relatively large share don't have any experiences with people with foreign background at all since most are retired and don't meet other people at work or at school.

Based on the measurement in 2018, the age group 51-65 years has the largest percentage of respondents reporting bad experiences (12\%) as compared to other age groups (7\%). 


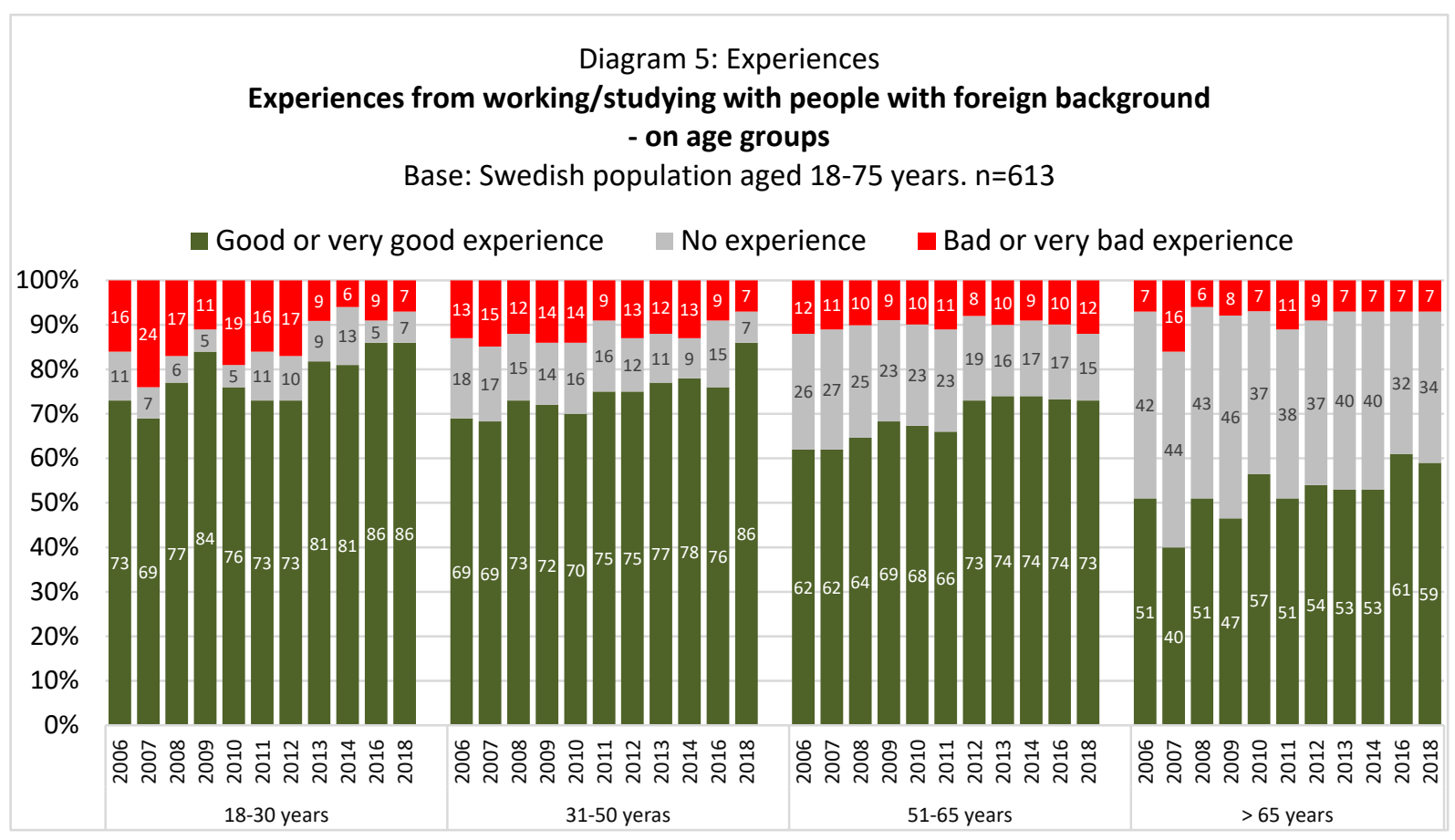

Diagram 5. Good and bad experiences of working or studying with people with foreign background (in age groups)

Education: There seems to be a strong correlation between level of education and having good experiences in school or at work with people with foreign background. The higher the respondent's education the better the experiences they report. A question that can be raised is whether people with higher education more often socialize with academics from other countries, thereby getting different experiences as compared to people with lower education, who interact with others with foreign background and lower education.

A larger share among people with university education have good experiences with people with foreign background, and this percentage has always been high since the measurements in The Diversity Barometer started in 2005. The percentage has increased over the years from $75 \%$ and stabilized at over $80 \%$ through the last 5 years. This recent measurement in 2018 had the highest result at $86 \%$.

Among respondents with high school education, the group with good experiences with people with foreign background in school or at work is a bit lower $(71 \%)$, which is also the highest measured in this group. There is a clear positive trend in experiences in this age group since 2013.

The experiences with people with foreign background in school and/or at work have also changed over the years for the group with only primary school education. The negative trend seen since 2014 has now stabilized at $47 \%$. It is worth noting that up to $44 \%$ respondents with primary school education report a lack of any experience with people with foreign background.

Respondents with high school education have the biggest percentage of people reporting bad experiences. 


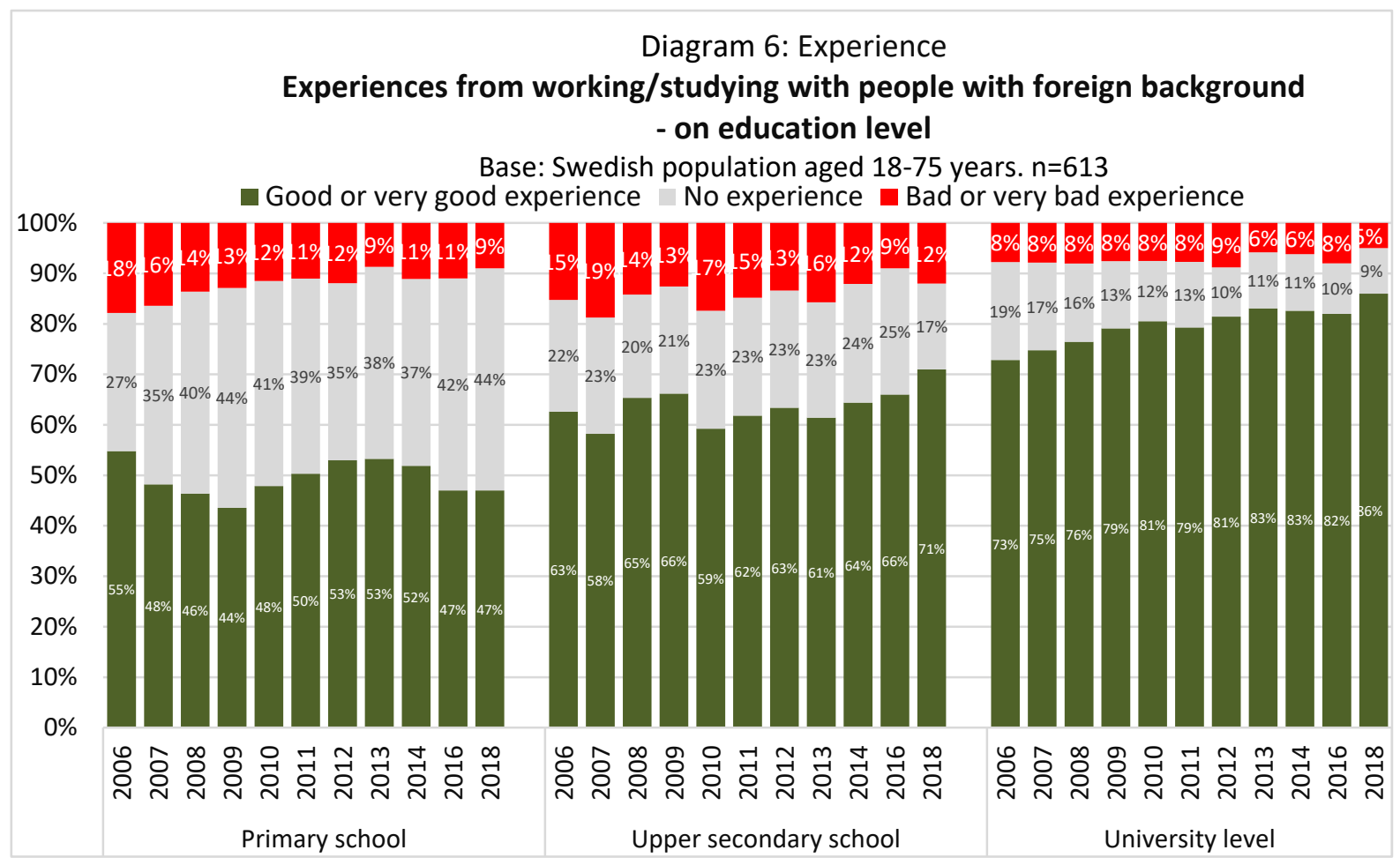

Diagram 6. Good and bad experiences of studying or working with people with foreign background (education)

To give a more correct picture of the effect of age and education on the individuals' experiences with colleagues with foreign background 2018, the correlation between these variables is calculated. The correlation for gender is not calculated because gender is not a continuous variable.

Table 1. Correlation between good experiences with people with foreign background in school or at work with age respectively level of education ${ }^{\mathrm{v}}$.

\begin{tabular}{|l|l|l|l|}
\hline \multirow{2}{*}{$\begin{array}{l}\text { Good experiences with people with foreign } \\
\text { background in school or at work }\end{array}$} & & Age & Level of education \\
\cline { 3 - 4 } & & -0.161 & 0.28 \\
\hline
\end{tabular}

As shown in table 1, there is a weak negative correlation between positive experiences and age $(-0.161)$, and a weak positive correlation between positive experiences and education level. This confirms that the older a person is, the less the positive experiences with people with foreign background. On the other hand, the higher the education level, the better the experiences.

\subsection{General Positive Attitudes Towards Diversity}

In this section, we present data on attitudes towards a number of positive statements about the rights and opportunities that people with foreign background, and their children, have in Sweden: preserving their culture, having same social rights as Swedish citizens, and preserving their native language.

Less than half $(46 \%)$ of the respondents have positive attitudes towards the Swedish society creating good conditions for people with foreign background to be able to preserve their culture when living in Sweden. The attitudes have been positive and quite stable across all measurements until the measurement in 2016 when a much lower index was recorded. The measurement in 2018 shows that the percentage accounting for positive attitudes towards creating conducive conditions for immigrants' cultural preservation has decreased to $46 \%$, the lowest ever measured in The Diversity Barometer since $2005^{\mathrm{vi}}$.

The percentage for respondents who disagree with the statement that society should create good conditions for people 
with foreign background to preserve their cultural traditions has previously been very stable over time. However, this attitude has now increased considerably by 8 percentage units and the result is the highest since 2005 .

In earlier measurements, most respondents have had positive attitudes towards the statement that people should have same social rights regardless of where they are born. This is an obvious example of the idea of equality that has great support in Sweden. There has been a positive trend from 2011 until the big decline in 2016. Although the measurement in 2018 at $61 \%$ shows some recovery, it is way below the previous high at $77 \%$. Nevertheless, the percentage of respondents that disagree with the statement on equal social rights is still on the lower side at $28 \%$.

The majority of respondents (56\%) agree totally or somewhat immigrants in Sweden should keep their native language and teach it to their children. Even though there has been some decline since 2016, this measurement is stable since 2005 , within the interval of $51-61 \%$. The percentage of respondents who do not agree with this statement is also relatively stable between $19-24 \%$, but with a slight increase in recent years.

Diagram 7 shows the Positive Attitude Index for each statement about diversity over the 13-year period since the measurements started. The purpose of the index is to show the trends in attitudes over time. Apart from the previously mentioned changes in attitudes towards social rights and cultural preservation in 2016, the diagram shows that all 3 variables have been relatively stable since 2005 . The attitudes towards immigrants' right to preserve their cultural are the least unfavorable.

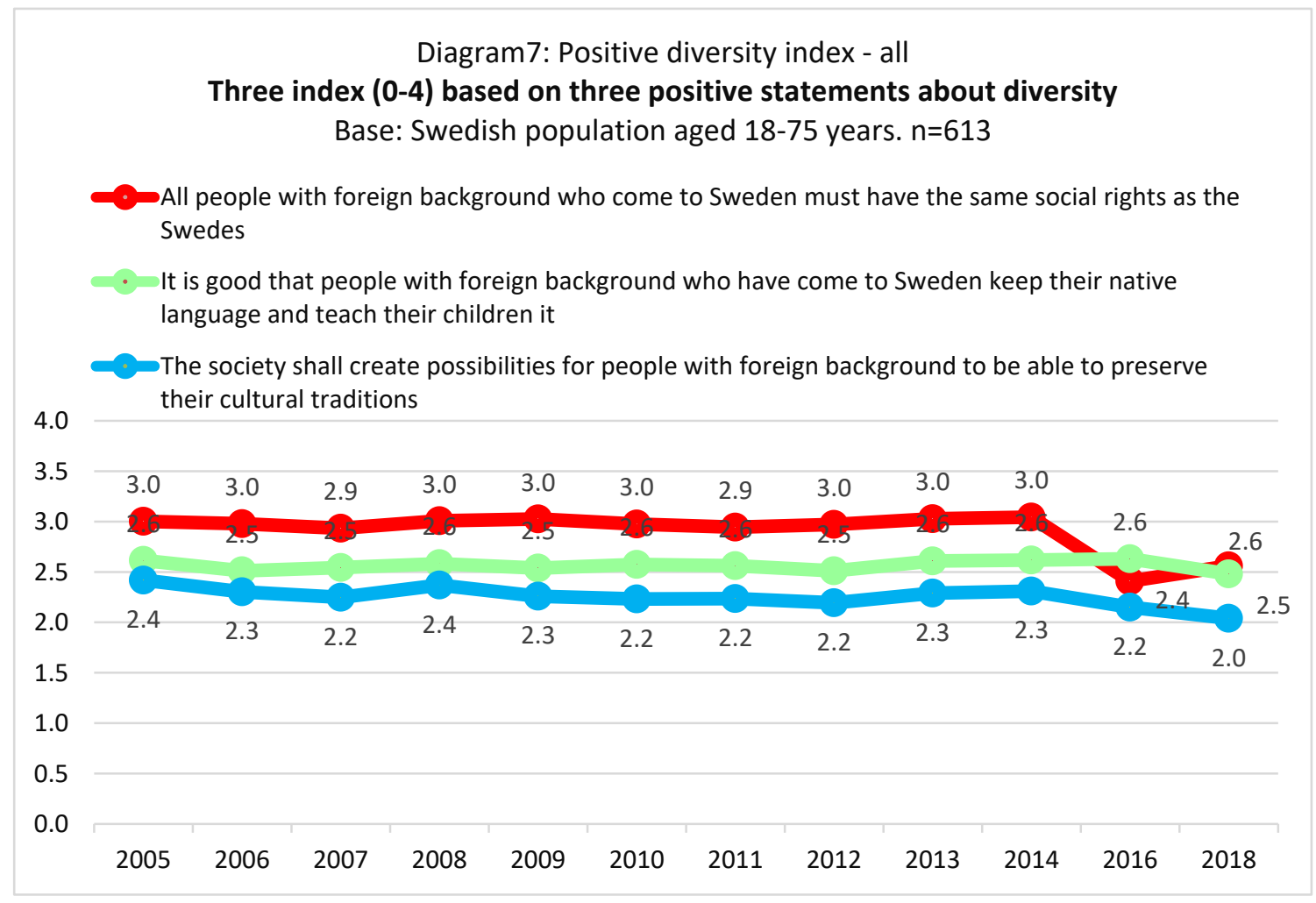

Diagram 7. Positive attitude index

To enable analysis of trends across socio-demographic groups, the results have been transformed into an index (4-0) rather than presenting only percentages as previously done. With this transformation, we get one value per year, with a higher average value indicating more negative attitudes.

As table 2 shows, there is a weak negative correlation between "variable 1-positive" and age (-0.218), whereas the correlation between "variable 1-positive" and education is positive but weak (0.214). 
Table 2. Correlation between positive statements about people with foreign background and age respectively level of education.

\begin{tabular}{|c|c|c|}
\hline & \multicolumn{2}{|c|}{ Pearson correlation } \\
\hline & Age & $\begin{array}{c}\text { Level of } \\
\text { education }\end{array}$ \\
\hline $\begin{array}{l}\text { Variable 1- positive: } \\
\text { All people with foreign background who come to Sweden } \\
\text { should have the same social rights as those who live here }\end{array}$ & -0.218 & 0.214 \\
\hline $\begin{array}{l}\text { Variable 2- positive: } \\
\text { It is good if people with foreign background who have } \\
\text { come and live in Sweden also keep their language and } \\
\text { teach their children this language }\end{array}$ & -0.239 & 0.295 \\
\hline $\begin{array}{l}\text { Variable 3- positive: } \\
\text { Society needs to create good conditions for people with } \\
\text { foreign background to preserve their own cultural } \\
\text { traditions }\end{array}$ & -0.177 & 0.223 \\
\hline
\end{tabular}

There is a weak negative correlation between "variable 2-positive" and age (-0.239), and weak positive correlation between "variable 2-positive" and education (0.295). There is a weak negative correlation between "variable 3-positive" and age (-0.177), and a weak positive correlation between "variable 3-positive" and education (0.223).

As shown in table 3, there is a weak positive correlation between "variable 1-negative" and age (0.147), and a weak negative correlation between "variable 1-negative" and education level (-2.287).

Table 3. Correlation between negative statements and age respectively level of education

\begin{tabular}{|l|l|l|l|}
\hline & \multicolumn{3}{|c|}{ Pearson correlation } \\
\cline { 2 - 4 } & & Age & Education \\
\hline $\begin{array}{l}\text { Many people with foreign background } \\
\text { only come to Sweden to take advantage of } \\
\text { the social benefits }\end{array}$ & 0.147 & -0.287 \\
\hline $\begin{array}{l}\text { All people with foreign background who } \\
\text { have commit crime in Sweden should be } \\
\text { forced to leave the country }\end{array}$ & 0.286 & -0.312 \\
\hline $\begin{array}{l}\text { Swedes feel more responsibility for their } \\
\text { job than people with foreign background } \\
\text { who have come to Sweden }\end{array}$ & 0.210 & \\
\hline
\end{tabular}

There is a weak positive correlation between "variable 2-negative" and age (0.286), and a weak negative correlation between "variable 2-negative" and education level (-0.312). There is a weak positive correlation between "variable 3 -negative" and age is (0.210), and a weak negative correlation between "variable 3-negative" and education level $(-0.280)$.

These results correspond to the results reported regarding the index for the positive statements.

\subsection{General Negative Attitudes Towards Diversity}

This section focuses on the general negative statements regarding diversity.

Four of ten respondents agree with the statement that immigrants come to Sweden to use the social welfare benefits 
offered in the country. The same percentage of respondents disagree. The attitudes towards among those who agree or disagree are very stable since the first measurement in 2005. The percentage of people who neither agree nor disagree has diminished a lot with the lowest value being reported in 2018. This could indicate polarization in attitudes related to the statement of use of social welfare benefits.

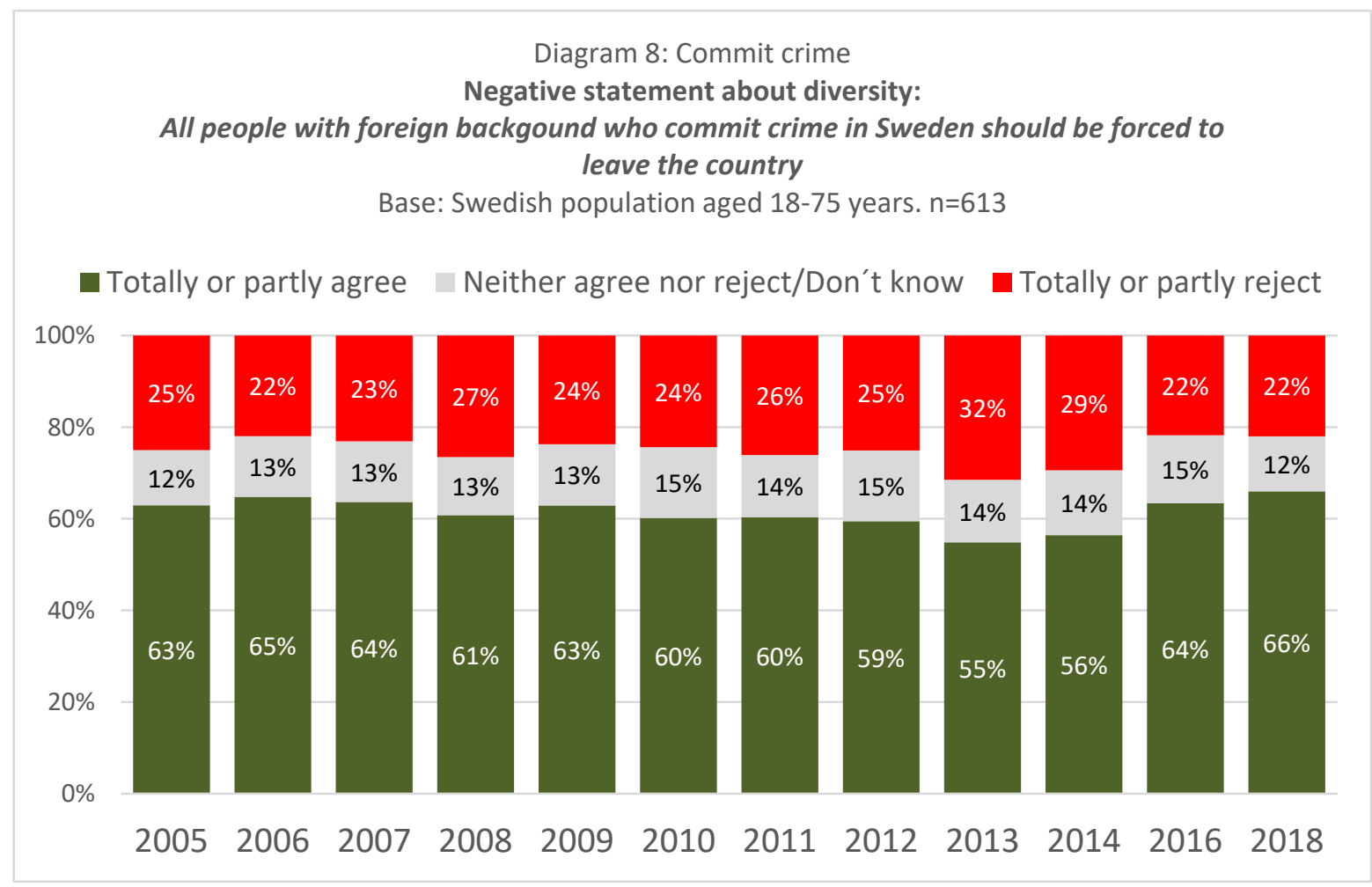

Diagram 8. Negative statement about diversity

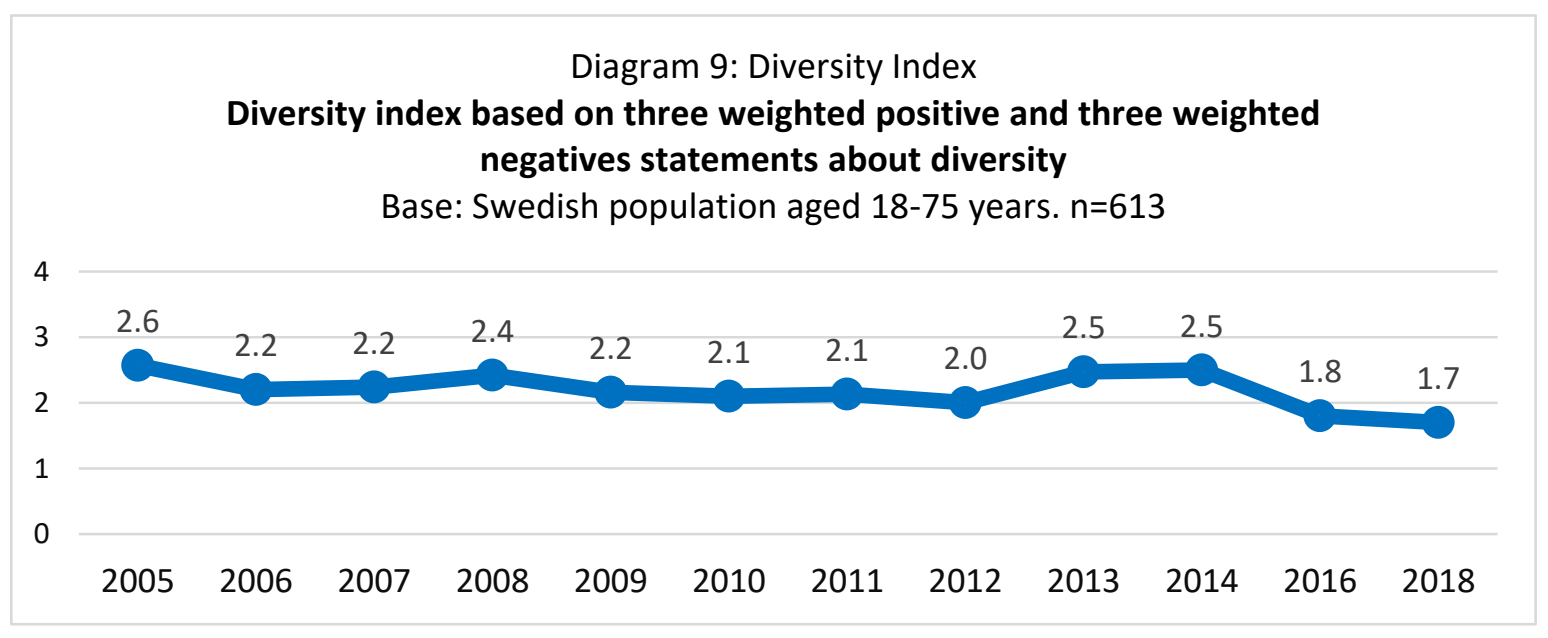

Diagram 9. Diversity Index 


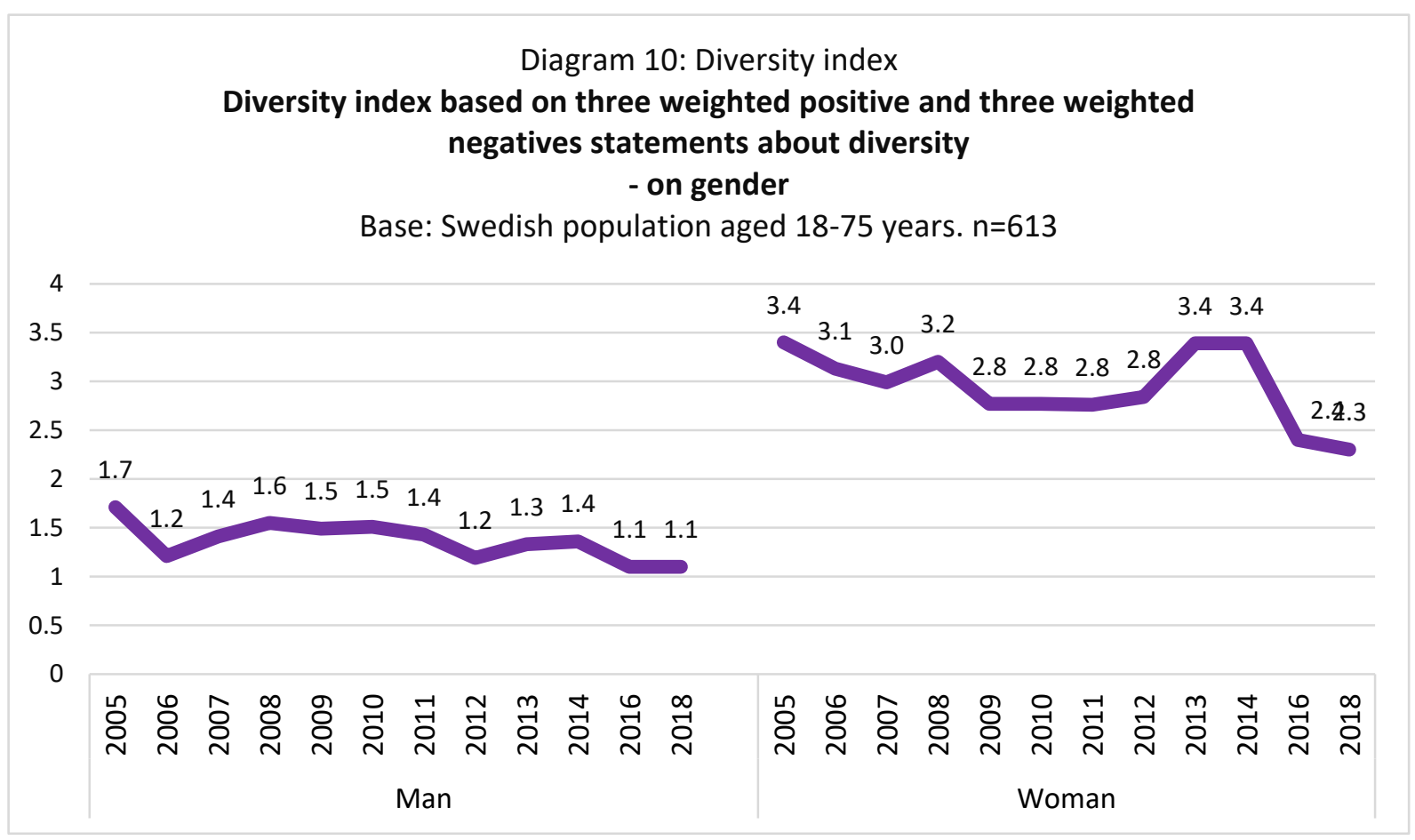

Diagram 10. Diversity index-Gender

The most negative attitudes towards diversity are related to the statement that people with foreign background who commit a crime should be forced to leave the country. After a couple of low measurements around 55\% in 2013 and 2014, the attitudes have deteriorated once again with almost similar measurements of 64\% and $66 \%$ in 2016 and 2018, indicating that majority of people agree with the above statement about immigrants and crime. These are close to measurements reported before 2012. It seems that committing crime as an immigrant arouses very negative feelings among the Swedes. The percentage of respondents who disagree with this statement is stable at $22 \%$ in 2016 and 2018, which break the negative trend reported in 2013 and 2014.

The attitude that ethnic Swedes would take more responsibility for their job than immigrants is relatively stable since 2005. In 2018, $17 \%$ of the respondents fall in the category that agrees with this statement. Majority disagree, and the percentage has been stable over time.

\section{Analysis and Discussion}

The aim of this article is to analyze changes in attitudes towards immigrants in Sweden since 2015. Based on a comparison between the results in The Diversity Barometer for 2005-2014, 2016, and 2018 we draw the following conclusions:

1. In general, there is augmentation of negative attitudes towards cultural diversity and immigration during the past years as compared to the period before 2016.

2. Swedes with lower education, men, older people, those who live in smaller cities or in the countryside and those with less contact with people with foreign background have more negative attitudes towards immigration and cultural diversity.

In our analysis, we have used theories and assumptions concerning political correctness, conflicts, group threat, as well as contact theory and tension theory. Our focus is on the larger contextual factors e.g. economic crisis, changes in population demographic, increased xenophobia, and how all these affect attitudes towards migration and ethnic diversity in Sweden.

From our data, we see that negative attitudes towards migration and ethnic diversity are partly related to the respondents' contact with immigrants. For example, all measurements indicate that the attitudes towards immigrants and ethnic diversity at work or in school are more positive than other attitudes. According to Contact Theory (Allport, 1954), there is a high risk of emergence of negative attitudes when minority and majority groups have limited contact or personal relations with each other. This could explain why respondents in our study who have had little or no interactions with people with foreign background have more negative attitudes towards immigrants. However, one condition that 
guarantees obtaining a positive view due through contact between different groups is that the contact takes place under similar conditions, with similar goals and through institutional support. Seen in this light, we can understand why segregation, which hinders the realization of such condition, can strengthen the negative attitudes (Semyonov $\&$ Glikman, 2009).

Another finding if our study is that people with a lower education level have more negative attitudes towards people with foreign background, whereas those with higher a level of education have more positive attitudes. This result is similar to other studies (e.g. Mella, 2011; Hainmueller, Michael \& Hiscox, 2007), which have established that highly educated people in Europe are more positive towards immigration and diversity. This could be explained by more intensive contacts that may happen between people with higher education, and immigrants who have been successfully integrated and established in their new homeland. Besides, people with high education, more than others, normally have anti-racist viewpoints.

On the other side, one wonders if the higher educational level does not mean a higher level of being more politically correct about issues regarding tolerance and attitudes towards immigrants. In this respect, Mella (2011) maintains that although higher education brings access to a broader international context that favor a better understanding of causes and consequences of migration processes, it gives access to an environment that can be unreliable when it comes to attitudes towards people in an emergency. Mella means that highly educated people can easily conceal their negative attitudes. In other words, a tendency of having more "politically correct" attitudes towards immigration can be more prevalent among highly educated people (Mella, 2011). During the past years in Sweden, with the intensification and normalization of anti-immigrant attitudes, some highly educated immigrants and their children have felt the intensification of negative attitude towards them. Kamali and Jönsson (2019) mention that as a result of the domination of neoliberal ideology and policies, critical and radical research is under constraints; academics with immigrant backgrounds are more subjected to such constraints because of "re-establishing white boys-networks" as well as "white girls-networks" at universities. Thus, racism and discrimination of academics with immigrant background has been dramatically increased.

Another factor that may explain the difference in attitudes towards immigration between highly educated and less educated people, is that the former often have more stable or permanent employment, and they feel less threatened by immigration. In an opposite manner, it is higher probability that people with lower education perceive that their job is under threat. According to the tension theory (Agnew \& Brezina, 2019), which focus on structural changes and their influence on individuals' attitudes, the sense of uncertainty and frustration that people experience when they have setbacks in life can be a source of negative attitudes and behavior, quite often directed towards "the other". This has been found to be true especially for less educated people or those in smaller societies.

It is also plausible that xenophobia and ethnocentrism is a result of prejudices. Collective prejudices can be the foundation to negative attitudes towards "the other". Thus, increased contact with, and knowledge about, immigrants may decrease the prejudices and reduce attitudes like xenophobia. This could explain why Swedes with more contact with people with foreign background have more positive attitudes towards immigrants and ethnic diversity, as shown by The Diversity Barometer.

Some studies (e.g. Brown, 1988) emphasize that under difficult social and economic conditions, perceived frustration can be expressed through increased prejudices against other ethnic groups. People become dissatisfied when they perceive a difference between what they have and what they consider they should have or could have, which increases their frustration against "the other". Frustration and discontent with the current situation can, according to the theory of tension, be directed towards another group when people feel powerless in their situation. The target for the negative attitudes can be anybody perceived as weaker (Einarsson, 1996).

Conflicts between groups can also arise when groups perceive that they have "incompatible goals", and when they compete for scarce resources, which can be material, status, power and or symbolic resources like the cultural heritage and values (Quilliams, 1995; Taylor \& Moghaddam, 1987; Knippenberg \& Ellemers, 1993).

With support from the theory of group conflict (Bobo, 1988) the increased negative attitudes towards immigrants and refugees can be explained by the worries about redistribution of resources (especially during economic difficulties in society) in combination with an unprotected labor market situation, and a drastic increase of immigrants (as happened in Sweden during 2015). Circumstances like these can have an impact on people who are financially exposed and they could see immigrants as a threat towards the labor market and the social welfare system (Lancee \& Pardos-Prado, 2013).

Attitudes towards immigrants are also related to non-economic factors, such as concerns for security (Mayda, 2006). In this respect, the dominated social discourses as well as the political climate in a society can strengthen both individual and collective prejudices, leading to negative attitudes. A study by Huysmans (2006) shows immigrants, especially Muslims, are in media and in some political contexts regarded as a threat against the European civilization and culture. 
Since certain political parties favor certain cultural characteristics, immigrants are consequently seen as a threat to the welfare system as well as the perceived western values such as equality, democracy and responsibility (Darvishpour \& Månsson, 2019).

The results from the two latest elections in Sweden (the parliamentary election in 2018 and election for the EU commission in 2019) indicated the significant growth in popularity of right-wing populist and immigrant-hostile party, the Sweden Democrats. This not only shows the increasing of negative attitudes towards immigration in Sweden, but also the normalization of the people's prejudices and negative attitudes towards immigration and diversity in the country.

Finally, the role of stigma in increasing the negative attitudes ought to be taken into consideration. According to some scientists (e.g. Strömbäck, Andersson \& Nedlund, 2017; Frost, 2007), it is not always only the anti-immigrant political parties and groups that create xenophobia discourses; the approach of the leading media to the problem of migration also plays an important role in people's attitudes towards immigrants. For example, pointing out immigrants as scapegoats can affect the vulnerable groups like less educated workers, who are in turn systematically affected by economic and structural changes. Studies by Kolankiewics (2015) and Strömbäck and Theorin (2018) show a relationship between attitudes towards cultural diversity and how the media is reporting about racism and xenophobia in Sweden. Strömbäck and Theorin (2018) show that media reporting on immigration in Sweden has had a negative impact on people's attitudes to immigration, especially in relation to immigration from the Middle East and Africa. Unfortunately, not all aspects of the multicultural relations are covered in the media, and less attention is paid to instances where the relations are working well, e.g. between people in housing areas, schools and workplaces. Therefore, the picture presented by is prejudiced.

\section{Conclusion}

As shown by other studies, (e.g. Public Opinion in the European Union, 2015; Meuleman, Evans \& Billiet, 2009), people in Sweden, more than other Europeans, have always shown the most positivity towards immigration in the European Union. However, more research is necessary to understand how national and global structural changes have influenced attitudes towards immigration and cultural diversity as observed in Sweden in the recent years. Multiculturalism has been perceived as a hinder to integration of people with foreign background, and some studies have investigated how multiculturalism negatively affects attitudes (Hainmuller, at.al., 2007; Vertovec, 2010). An interesting hypothesis that needs to be take into consideration in further studies about attitudes towards immigration and diversity is that the increase of the negative attitudes towards immigrants is to be found during transition to post industrialism and neoliberal politics (Rydgren, 2017).

Between 2000 and 2020, welfare systems over the world, including Sweden, have been affected by globalization (Fook, 2002; Stepney \& Popple, 2008). Thus, it is crucial to investigate how reducing welfare benefits has affected attitudes towards migration and ethnic diversity. The question remains whether economic and cultural threats can explain xenophobia (Hjerm \& Nagayoshi, 2011).

The results from The Diversity Barometer 2016 and 2018 show that negative attitudes to ethnic and cultural diversity have increased. Thus, this issue, together with discourses on marginalization and social exclusion, is highly relevant to social work practice and research. As we point out negative attitudes toward immigrant and ethnic diversity in a society may lead to negative consequences on immigrant's income and overall wellbeing, and normalization discrimination if immigrant groups.

\section{References}

Agnew, R., \& Brezina, T. (2019). General Strain Theory. In M. D. Krohn, N. Hendri, G. P. Hall,\& A.J. Lizotte (ed.). Handbook on Crime and Deviance. Springer. https://doi.org/10.1007/978-3-030-20779-3_8

Ahmadi, F., \& Palm, I. (2018). Mångfaldsbarometern 2018. Gävle University Press. Retrieved from https://www.hig.se/download/18.321e5b271641cca84643f3ba/1534110403023/Mångfaldsbarometern_2018.pdf

Ahmadi, F., Darvishpour, M., Ahmadi, N., \& Palm, I. (2018). Diversity Barometer: Attitude changes in Sweden. Nordic social Work Research, 10(1), 21-38. https://doi.org/10.1080/2156857X.2018.1527242

Ahmadi, F., Mella, O., Palm, I., \& Darvishpour, M. (2015). Mångfaldsbarometern: tio år av attitydmätningar i Sverige. Gävle: Gävle University Press.

Ahmadi, F., Palm, I., \& Ahmadi, N. (2016). Mångfaldsbarometern 2016. Gävle University Press. Retrieved from https://www.hig.se/download/18.62385c32157b0d73e1d2578e/1476908317545/Högskolan+i+Gävle_Mångfaldsba rometern+2016.pdf

Allport, G. W. (1954). The Nature of Prejudice. Cambridge, Mass.: Addison-Wesley. 
Asztalos Morell, I., \& Darvishpour, M. (2018). The securitization of asylum-seeking in Sweden after 2015 in light of experiences of asylum-seeking adolescent girls with roots in Afghanistan. In D. Siegel, \& V. Nagy (Eds.) The migration crisis? - Criminalization, security and survival, (pp.363-389). The Hague: Eleven international publishing.

Bobo, L. (1988). Group conflict, prejudice and the paradox of contemporary racial attitudes. In: P.A. Katz, \& D. A. Taylor (Eds.), Eliminating racism: Profiles in controversy (pp 85-114). New York: Springer. https://doi.org/10.1007/978-1-4899-0818-6_5

Brown, R. (1988). Group processes. Dynamics within and between groups. Oxford: Blackwell Publishers.

Bursell, M. (2015). Inkludering och exkludering på den svenska arbetsmarknaden. In M. Darvishpour, \& C. Westin (Eds.), Migration och etnicitet: perspektiv på ett mångkulturell Sverige. Lund: Studentlitteratur.

Darvishpour, M., \& Månsson, N. (2019.) Ensamkommandes upplevelser och professionellas erfarenheter - integration, inkludering \& jämställdhet. Malmö: Liber.

Darvishpour, M., \& Westin, C. (Eds.). (2015). Migration och etnicitet: perspektiv på ett mångkulturell Sverige. Lund: Studentlitteratur.

Einarsson, C. (1996). Konflikter mellan grupper. Teorier om intergruppskonflikter. FOG-rapport, nr. 33. Linköping: Institutionen för beteendevetenskap Linköpings universitet.

Fook, J. (2002). Social work: critical theory and practice. London: Sage.

Frost, D. (2007). The 'enemy within'? Asylum, racial violence and 'race hate' in Britain today. Twenty-First Century Society, 2(3), 227-248. https://doi.org/10.1080/17450140701631411

Hainmuller, J., Michael, J., \& Hiscox, M. (2007). Educated preferences: Explaining Attitudes toward Immigration in Europe. International Organization, 61(2), 399-442. https://doi.org/10.1017/S0020818307070142

Hjerm, M., \& Nagayoshi, K. (2011). The composition of the minority population as a threat. Can real economic and cultural threats explain Xenophobia? International Sociology, 26, 815-843. https://doi.org/10.1177/0268580910394004

Huysmans, J. (2006). The politics of insecurity: fear, migration and asylum in the EU. Hoboken: Taylor \& Francis Ltd. https://doi.org/10.4324/9780203008690

Kamali, M., \& Jönsson, H. J. (2019). Revolutionary Social Work: Promoting sustainable justice. Critical and Radical Social Work, 7(3), 293-314. https://doi.org/10.1332/204986019X15688881109268

Knippenberg, D. V., \& Ellemers, N. (1993). Strategies in intergroup relations. In: M. A. Hogg, \& D. Abrams (Eds.). Group motivation. Social psychological perspectives. New York: Harvester Wheatsheaf.

Kolankiewics, M. (2015). Anti-Muslim Violence and the Possibility of Justice. Lund Dissertations in Sociology 109.

Lancee, B., \& Pardos-Prado, S. (2013). Group Conflict Theory in a Longitudinal Perspective: Analyzing the Dynamic Side of Ethnic Competition. International Migration Review, 47(1), 106-131. https://doi.org/10.1111/imre.12015

Mayda, A. M. (2006). Who is against immigration? A cross-country investigation of individual attitudes toward immigrants. The Review of Economics and Statistics, 88(3), 510-530. https://doi.org/10.1162/rest.88.3.510

Mella, O. (2011). Mångfaldsbarometern. Sju år av attitydmätningar. Sociologisk forskning, 48(4), 45-53.

Meuleman, B., Evans, E., \& J. Billiet, J. (2009). Changing attitudes toward immigration in Europe, 2002-2007: A dynamic group conflict theory approach. Social Science Research, 38(2), 352-36. https://doi.org/10.1016/j.ssresearch.2008.09.006

Migrationsverket. (2018). Ensamkommande barn. Retrieved from https://www.migrationsinfo.se/migration/sverige/asylsokande-i-sverige/ensamkommande-barn/

OM-rapport 2017:32. Svenska trender 1986-2016 [SOM Report 2017: 32. Swedish trends 1986-2016]. Retrieved from https://som.gu.se/digitalAssets/1649/1649642_32-svenska-trender-1986-2016.pdf

Perry, B. (2001). In the Name of Hate: Understanding Hate Crime. London \& New York: Routledge. https://doi.org/10.4324/9780203905135

Public Opinion in the European Union. 2015. Standard Eurobarometer 83, European commission. Retrieved from https://ec.europa.eu/commfrontoffice/publicopinion/archives/eb/eb83/eb83_eu.htm

Rydgren, J. (Ed.) (2017). The Oxford Handbook of the Radical Right. Oxford: Oxford University. https://doi.org/10.1093/oxfordhb/9780190274559.001.0001 
Semyonov, M., \& Glikman, A. (2009). Ethnic Residential Segregation, Social Contacts, and Anti- Minority Attitudes in European Societies. European Sociological Review, 25(6), 693-708. https://doi.org/10.1093/esr/jen075

Siegel, D., \& Nagy, N. (Ed.) (2018). The migration crisis? - Criminalization, security and survival. The Hague: Eleven international publishing.

Stepney, P., \& Popple, K. (2008). Social Work and the Community: A Critical Context for Practice. New York: Palgrave Macmillan. https://doi.org/10.1007/978-1-137-08834-5

Strömbäck, J., \& Theorin, N. (2018). Attityder till invandring - en analys av förändringar och medieeffekter i Sverige 2014-2016, DELMI rapport, 2018:4.

Strömbäck, J., Andersson, F., \& Nedlund, E. (2017). Invandring i medierna: hur rapporterades svenska tidningar åren 2010-2015? Stockholm: Delmi.

Taylor, D. M., \& Moghaddam, F. M. (1987). Theories of intergroup relations. International social psychological perspectives. New York: Preager Publishers.

Vertovec, S. (2010). Towards post-multiculturalism? Changing communities, conditions and contexts of diversity. International Social Science Journal. https://doi.org/10.1111/j.1468-2451.2010.01749.x

Waisman, G., \& Larsen, B. (2016). Income, Amenities and Negative Attitudes. IZA Journal of Development and Migration, 5(1). https://doi.org/10.1186/s40176-016-0056-0

Wigerfelt, B., \& Wigerfelt, A. S. (2017). Hatbrott med främlingsfientliga och rasistiska motiv: en kunskapsöversikt. Stockholm: Delegationen för migrationsstudier.

\title{
Closing remarks:
}

\begin{abstract}
${ }^{\mathrm{i}}$ The attitudes among the Swedish people towards immigrants are also studied yearly in the national SOM-surveys. As many investigations (SOM report, 2017, p.32) shows that the public opinion regarding immigration and refugees has been more positive during the last decades. The trend has continued up to 2015. In 2016 the negative attitudes toward receiving refugees started to increase drastically; 52 percent wanted to receive fewer refugees, 37 percent were worried about the increased number of refugees, while 45 percent were worried over an increased xenophobia, which showed a dramatically increase and polarization within the public opinion (SOM report, 2017, p.32).
\end{abstract}

ii SPAR is short for Swedish Population Register, which is a public register including all people who are registered in Sweden.

iii This means that a sample that has been used in this study is calculated to 13 percent among the Swedish adults and the actual number of the population is 22 percent. This means that it is a shortage of eight percentage units in the sample compared to the actual population. This is not surprising since the study was a questionnaire that was postal written in Swedish only. The lower number of people with foreign background in the sample can also depend on the fact that the sample only includes the Swedes 18 years or above. The difference in the sample and the population is therefore probably even less than the difference of eight percent.

iv There are no significant differences between men and women, different age groups or different education level regarding how often they socialize with people from other parts of the world. It doesn't matter if it is about socializing with people from Asia, Middle East, Africa or any other part of the world.

${ }^{v}$ Used scale for the correlation analysis

\begin{tabular}{|c|c|c|c|c|c|c|c|c|c|}
\hline \multicolumn{2}{|c|}{ AGE } & \multicolumn{2}{|c|}{ LEVEL OF EDUCATION } & \multicolumn{2}{|c|}{ GENDER } & \multicolumn{2}{c|}{$\begin{array}{c}\text { EXPERIENCES FROM } \\
\text { COLLEAGUES WITH } \\
\text { FOREIGN BACKGROUND }\end{array}$} & \multicolumn{2}{c|}{ ATTITUDES } \\
\hline 1 & $18-30$ years & 1 & Primary school & 1 & Man & 1 & Very bad & 1 & Totally disagree \\
\hline 2 & $31-50$ years & 2 & Upper secondary school & 2 & Women & 2 & Quite bad & 2 & Somewhat disagre \\
\hline 3 & $51-65$ years & 3 & University level & & & 3 & No experience & 3 & Neither agree nor disagree \\
\hline 4 & Older than 65 years & & & & & 4 & Quite good & 4 & Somewhat agree \\
\hline & & & & & & 5 & Very good & 5 & Totally agree \\
\hline
\end{tabular}

The following ranking has been used to explain the strength in the correlations.

- 1 = Perfect positive correlation

- $0.50-0.99=$ Strong positive correlation 
- $0-0.49=$ Weak positive correlation

$\bullet 0$ = No correlation

$\bullet 0--0.49=$ Weak negative correlation

- $-0.50--0.99=$ Strong negative correlation

$\bullet-1=$ Perfect negative correlation

${ }^{v i}$ There are not significant differences among different social groups in the society regarding the attitudes towards the statement if the society should create good opportunities for immigrants to preserve their culture in Sweden. Society should create possibilities for immigrants to be able to preserve their cultural traditions. Women are more positive than men to this statement, younger people are more positive than older people, and people with higher education are more positive than those with low education. The attitudes are gradually more negative the older they are and the lower education they have.

\section{Copyrights}

Copyright for this article is retained by the author(s), with first publication rights granted to the journal.

This is an open-access article distributed under the terms and conditions of the Creative Commons Attribution license which permits unrestricted use, distribution, and reproduction in any medium, provided the original work is properly cited. 